\title{
Recent climate change affecting rainstorm occurrences: a case study in East China
}

\author{
M. Domroes and D. Schaefer \\ Department of Geography, Mainz University, Germany \\ Received: 8 February 2008 - Published in Clim. Past Discuss.: 13 March 2008 \\ Revised: 1 September 2008 - Accepted: 7 October 2008 - Published: 27 November 2008
}

\begin{abstract}
The paper aims to investigate the occurrences of rainstorms and their relationship with the climate change scenario. The study period under investigation refers to the period of greatest recent warming between 1976-2000 whereas the study area covers China east of $105 \mathrm{E}$ longitude. This region is commonly considered to be controlled by the monsoon type of climate over East Asia.

Positive (increasing) trends of rainstorm occurrences, both in annual and summer respects, have been shown for subtropical China whereas a non-uniform picture is associated with temperate China. The increase of rainstorms in subtropical China corresponds with an increasing trend of precipitation. At the same time, subtropical China experiences a mostly decreasing recent temperature change. No clear evidence could, however, be proved for a direct linkage between increasing temperatures and greater rainstorm occurrences. Within the climate change scenario a great risk of rainstorm occurrences must be regarded as part of the increasing risk of extreme weather events.

Rainstorm occurrences are of a great practical importance as they increase the risk for environmental hazards such as landslides, landslips and floods. Landuse planners must therefore pay a great attention to an increasing number of rainstorms and their adverse risk impact on the environment.

Such practical aspects need particular attention in subtropical China as the region of largest increase of rainstorm occurrences and where, at the same time, the mountains and hilly landscapes are particularly hazard-prone to landslides and floods.
\end{abstract}

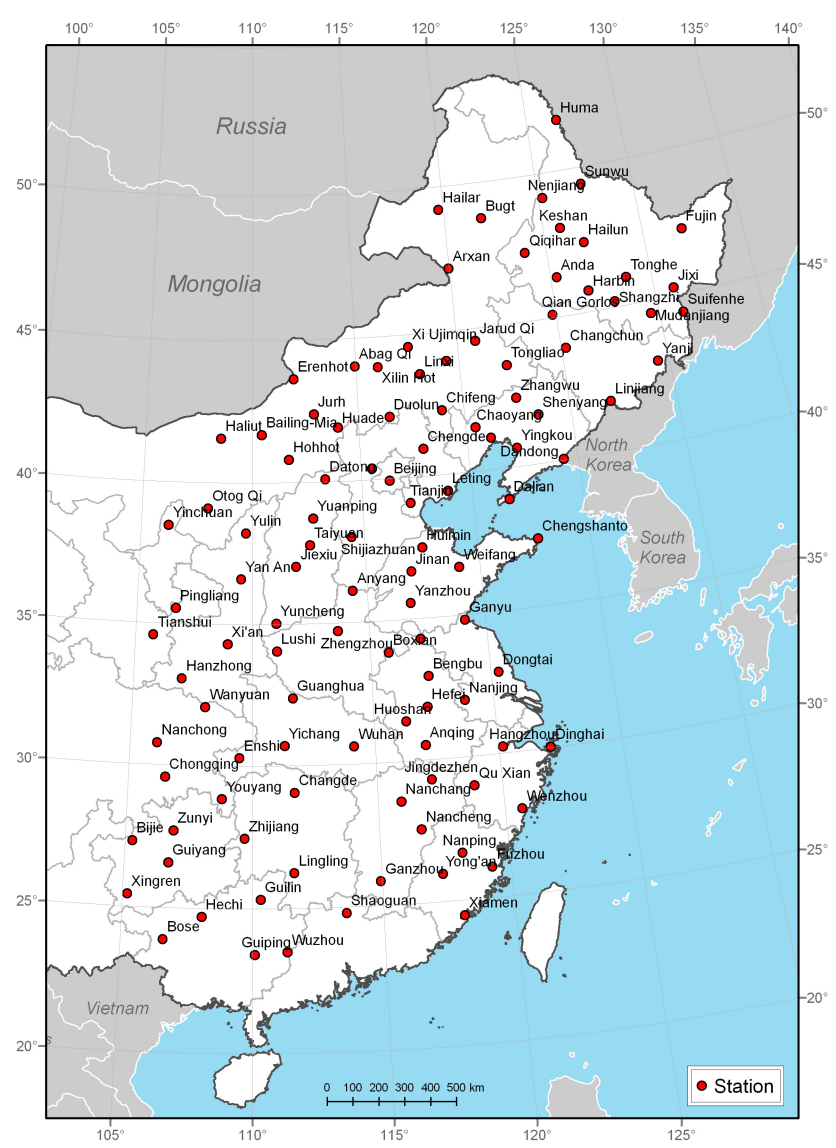

Fig. 1. China east of $105^{\circ} \mathrm{E}$ and location of stations under study. 


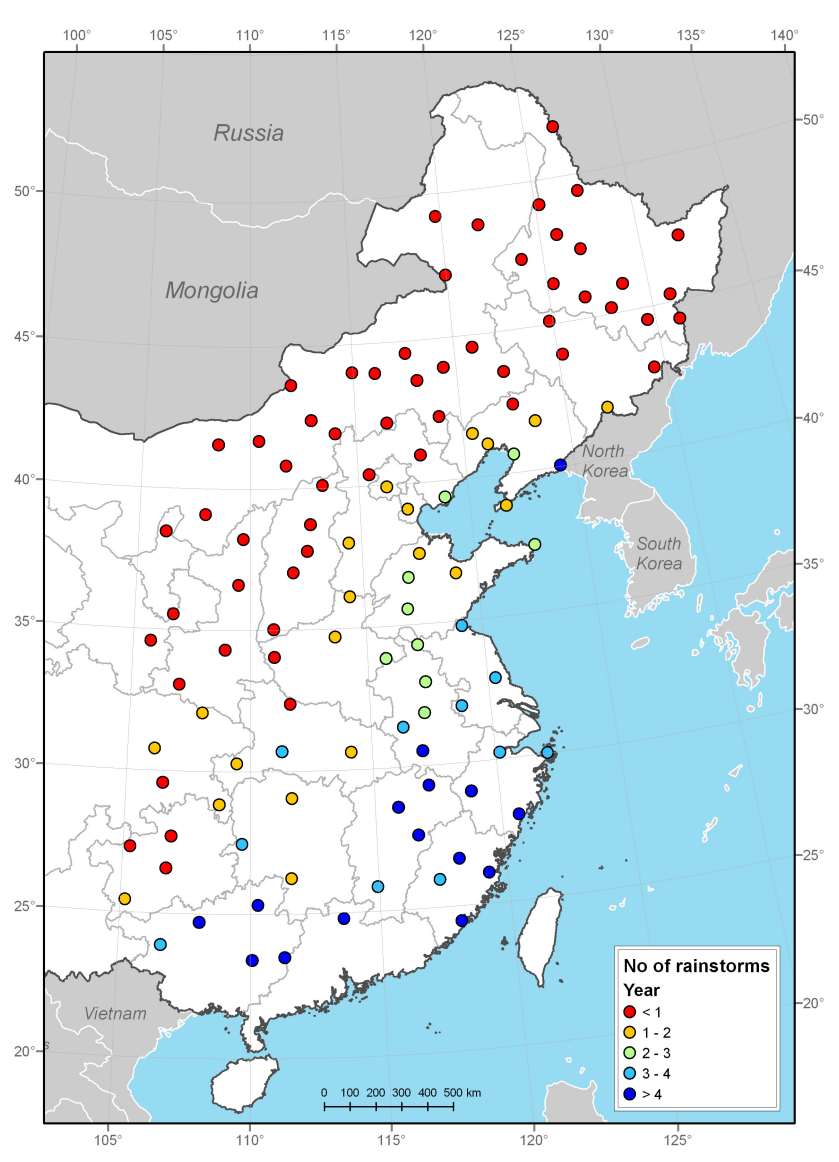

Fig. 2. Number of rainstorms/year over East China, 1976-2000.

\section{Introduction}

The climate change scenario is, in a global approach, well documented with the status of knowledge deliberately described in the Fourth IPCC Assessment Report (IPCC, 2007) which updated the previous report (IPCC, 2001). Global mean surface temperatures have risen by $0.74^{\circ} \mathrm{C} \pm 0.18^{\circ} \mathrm{C}$ when estimated by a linear trend over the past 100 years (1906-2005) (IPCC, 2007). The trend given is larger than the trend for the period $1901-2000$ at a rate of $0.6^{\circ} \pm 0.2^{\circ} \mathrm{C}$ (IPCC, 2007). The rate of warming over the past 50 years is almost double that over the past 100 years $\left(0.13^{\circ} \mathrm{C} \pm 0.03^{\circ} \mathrm{C}\right.$ vs. $0.07^{\circ} \mathrm{C} \pm 0.02^{\circ} \mathrm{C}$ per decade). The IPCC Report (2001) demonstrates that increase in global temperatures since the late 19th century occurred in two distinct periods: 19101945 and 1976-2000. The latest IPCC Report (2007) clearly states the ongoing evolution of global warming in the present century. Strengthening of warming in the most recent decades is remarkably shown by the observation that 11 of the last 12 warmest years (1995-2006) rank among the 12 warmest years over the instrumental record of global surface temperature (since 1850), IPCC (2007).

The IPCC Report (2007) gives also evidence that recent climate temperature increase is chiefly related to win-

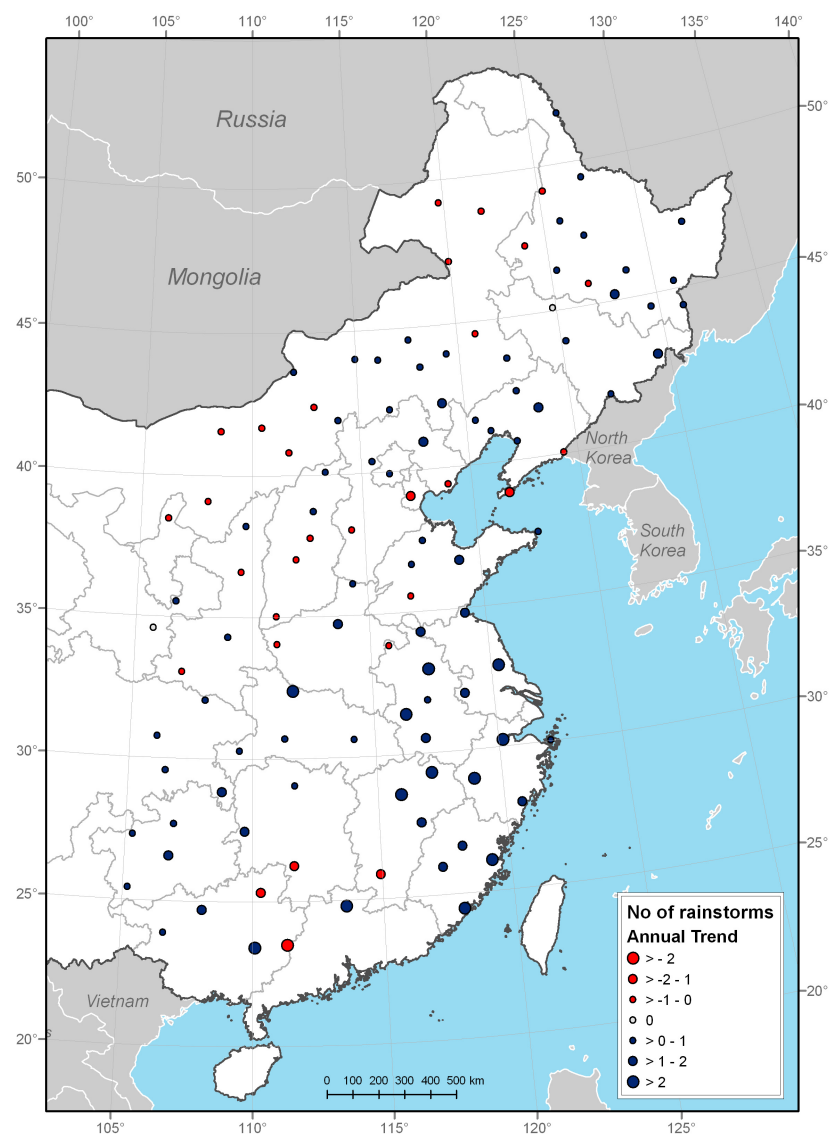

Fig. 3. Trend of number of rainstorms/year over East China, 19762000 .

ter and spring (December-February, resp. March-May) in the Northern Hemisphere. Truly existing are also remarkable spatial variabilities of recent climate change with highest warming trends over the northern land-surface occupying Northern America and Eurasia, including China.

Climate change has meanwhile become a major subject of research in China showing temperature increases and changes of other climatic parameters at different rates over different parts of China (see, for example, Ren et al., 2005, and comprehensive list of references given therein). The present authors have given a detailed description of warming in China using 50-yr (1951-2000) data for 165 WMOapproved meteorological stations (Domroes and Schaefer, 2003). It is shown that positive temperature trends prevail at most stations in China. Furthermore, the magnitude of increase varies over space, mostly at rates between $0.5-1.0^{\circ} \mathrm{C}$ with the greatest warming trend of $2.6^{\circ} \mathrm{C}$, referring to the 50-yr period 1951-2000. Corresponding with the global observations, also in China annual temperature increase results mainly from increasing winter temperatures. Summer temperatures were observed as slightly decreasing over most parts of China (Domroes and Schaefer, 2003). 


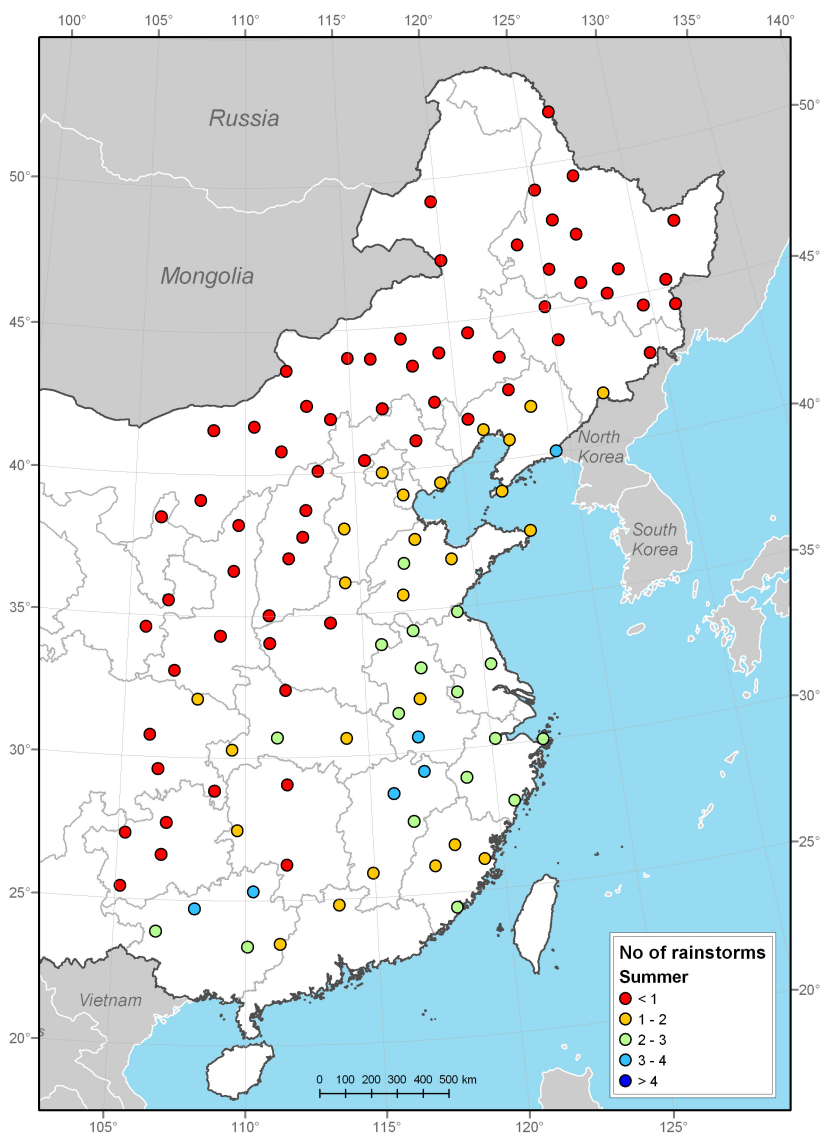

Fig. 4. Number of rainstorms/summer (June-July-August) over East China, 1976-2000.

With reference to climate change, precipitation is highly variable over space and time. Focusing on Asia, increasing precipitation has been observed over central Asia opposite to decreasing trends over parts of southern Asia (IPCC, 2007). Positive and negative trends of precipitation were observed in China for 1951-2000 (Domroes and Schaefer, 2003): Increasing trends, up to $100 \mathrm{~mm}$, were experienced in South China whereas decreasing trends up to $100 \mathrm{~mm}$ were observed over North China (for details see Domroes and Schaefer, 2003).

As a consequence of temperature change increasing occurrences of extreme weather events are likely supposed, including rainstorms, associated with negative impacts on the environment, such as landslides and soil erosion.

\section{Aim of the paper}

The paper aims to investigate whether the occurrences of rainstorms are directly associated with climate change, particularly with temperature increase; the study area covers East China, defined east of $105 \mathrm{E}$ longitude. This region is commonly considered to be controlled by the monsoon

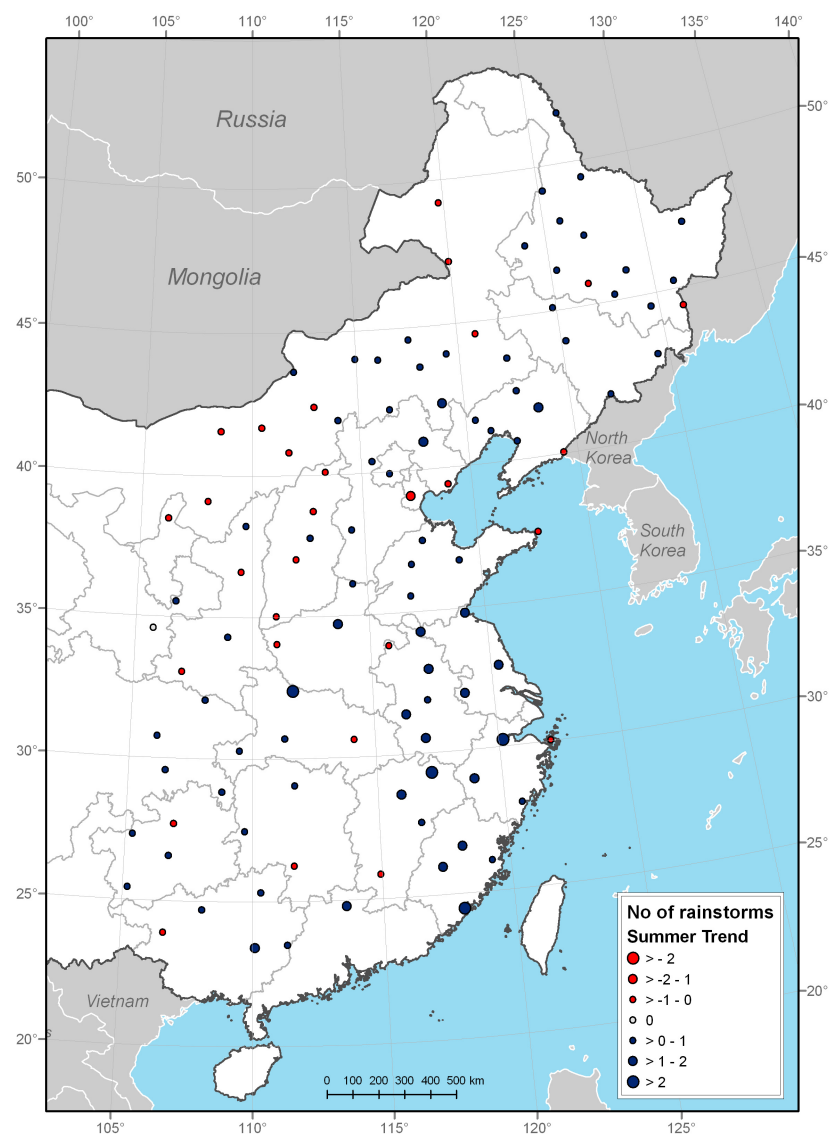

Fig. 5. Trend of number of rainstorms/summer (June-July-August) over East China, 1976-2000.

type of climate over East Asia (Domroes and Peng, 1988). The study period 1976-2000 covers the period of strongest warming within the recent evolution of global surface temperature increase since instrumental records (IPCC, 2001). The climatic parameters to be investigated for rainstorm occurrences are therefore related to the 25 years 1976-2000.

\section{Data and method of study}

Daily precipitation data were evaluated for 112 meteorological stations over East China (Fig. 1). Data were taken from the quality checked "Global Historical Climatology Network" edited by the (US) National Climatic Data Center (NCDC, 2008). Rainstorm analyses were, on the one side, carried out for the annual occurrences and, on the other, for summer occurrences as summer (June-July-August, JJA) represents the peak season of precipitation and subsequently of rainstorms. The length of the summer rainy season obviously varies over the vast space of China showing JJA as the peak rainy months (Domroes and Peng, 1988).

Particular reference is paid to the 25-year study period 1976-2000 (see para 2) which, though climatologically and 


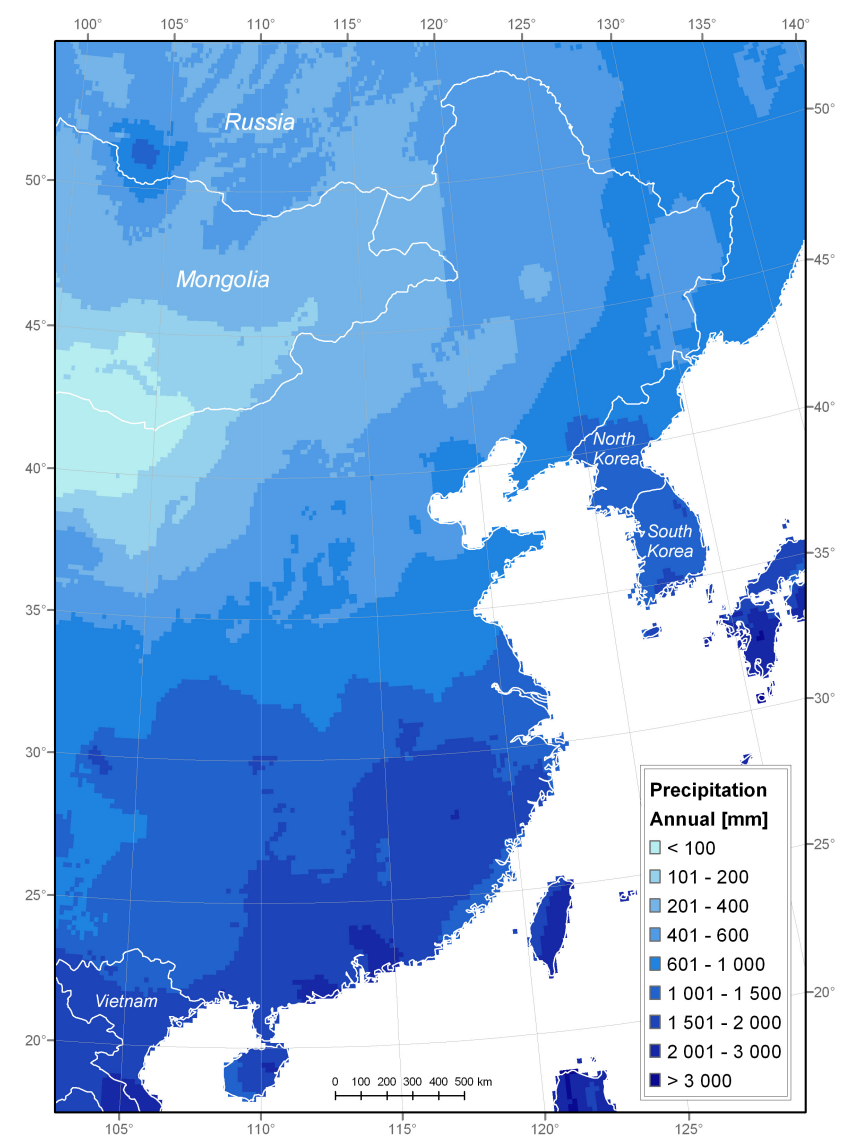

Fig. 6. Mean annual totals of precipitation over East China, 19512000 .

statistically below the 30 years standard of climatic normals, corresponds with the given period of greatest warming, according to IPCC.

In order to analyze trends of rainstorm occurrences, two methods which are commonly used in climate change research were applied: the least-square method for computing linear trends, and the non-parametric approach (after MannKendall) for detecting all trends - no matter of their form.

For the present paper the definition of rainstorm by a rainfall total $>50 \mathrm{~mm} / 24 \mathrm{~h}$, according to Tao (1980), was applied. Recommended by Tao in his comprehensive handbook on "Severe Rainstorms in China" (1980, in Chinese) this threshold has meanwhile become a widely accepted criterion. This value is, at the first sight, rather high but it distinctly detects exceptionally strong rainfall events. Therefore, such rainstorms can be considered as a genuine part of extreme weather events discussed under the climate change scenario.

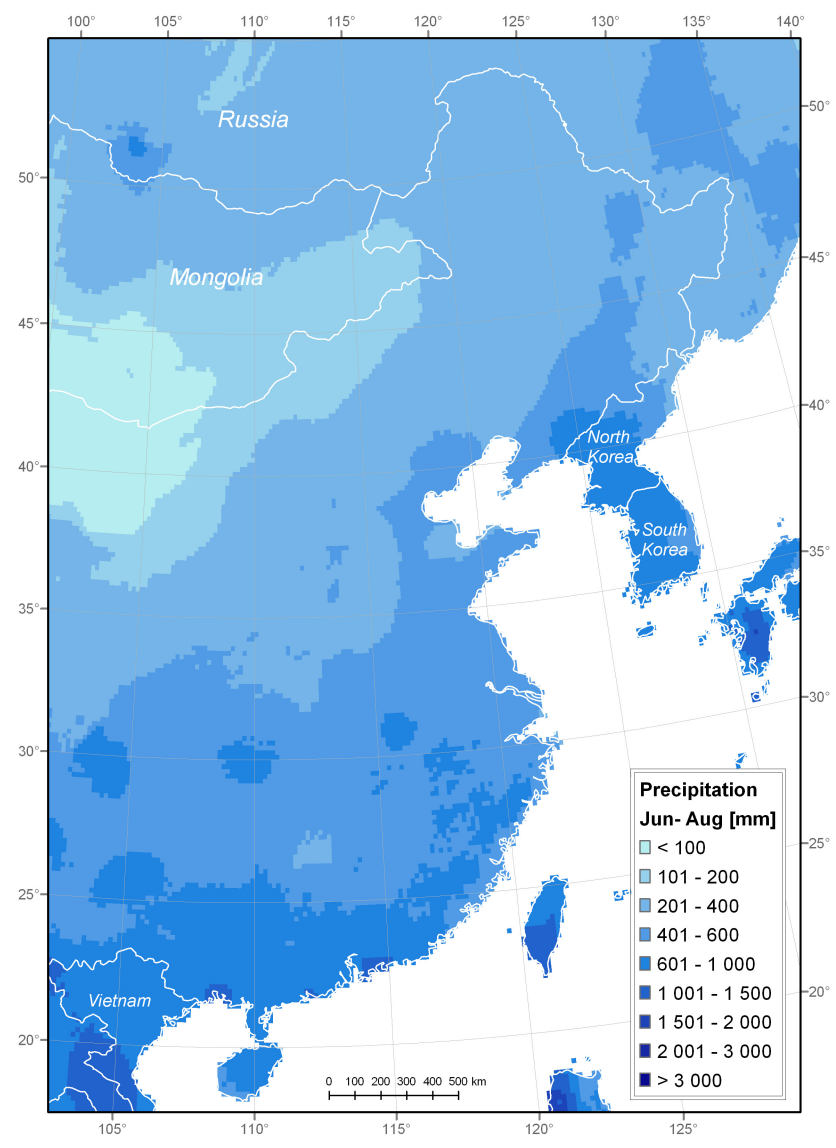

Fig. 7. Summer (June-July-August) totals of precipitation over East China, 1951-2000.

\section{Results}

\subsection{Annual occurrences of rainstorms}

Typically to be seen, rainstorm occurrences are unevenly distributed over space (Fig. 2). Most regions experience only a small number (below 3 annual events of rainstorms). A larger number (above 4, at the most 7 events) occurs only over smaller regions. Spatially, a greater number of rainstorms occurs over southern and southeastern China (generally called Subtropical China, see the widely accepted climate classification of China by Huang Bing-Wei, in Domroes and Peng, 1988). A smaller number of rainstorms occurs however over northern China (identified as Temperate China, see Huang Bing-Wei). Hence, a distinct south-to-north gradient of decreasing rainstorm occurrences can be observed.

\subsection{Trend of annual occurrences of rainstorms}

The trend of the annual number of rainstorms (Fig. 3) is shown with blue symbols in case of a positive (= increasing) trend and with red symbols in case of a negative (= decreasing) trend. The number of rainstorms is classified as follows: in case of increasing rainstorms $>0$ to $1,>1$ to 2 , and $>2$, 


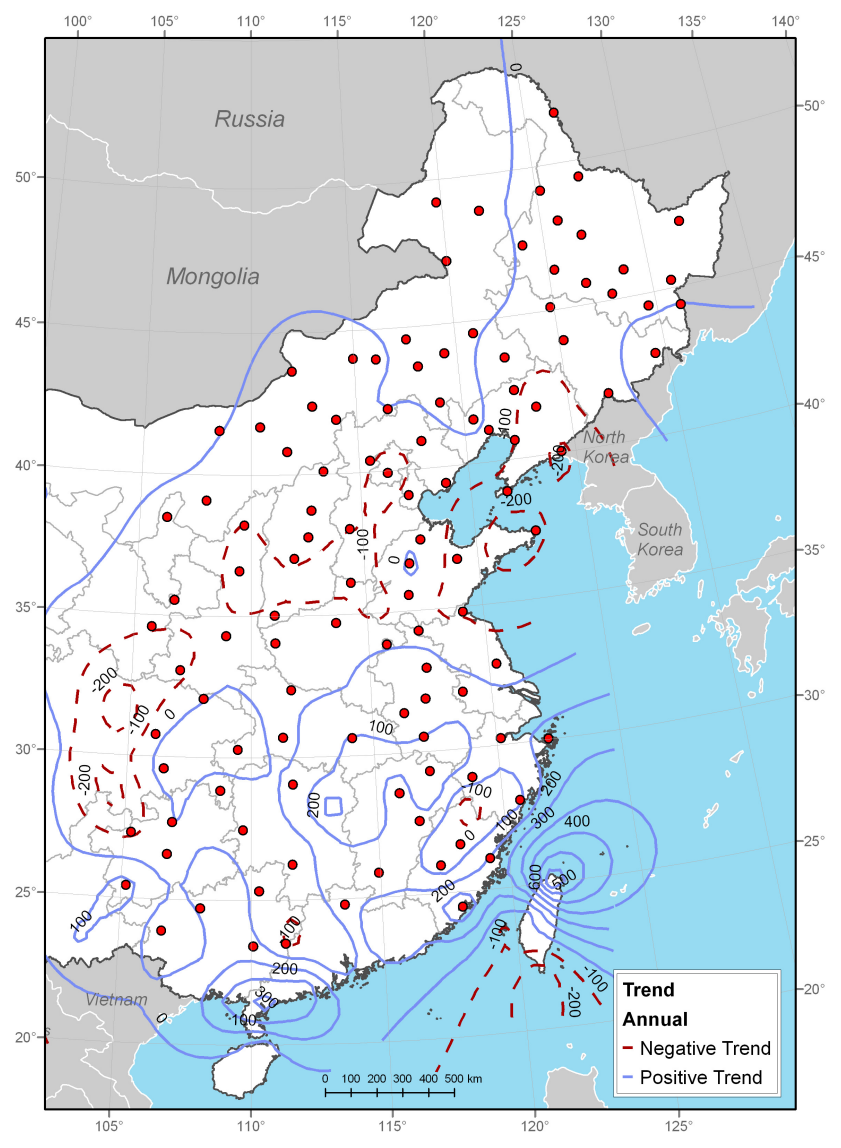

Fig. 8. Trend of annual precipitation over East China, 1951-2000, $\mathrm{mm} / 50$ years

(Domroes and Schaefer, 2003)

in case of decreasing rainstorms: $<0$ to $-1,<-1$ to -2 , and $>2$. In both cases, positive and negative trends are related to the 25 yr observation period 1976-2000.

As to be seen (Fig. 3) a positive trend occurs at the majority of stations. The magnitude of trend is, however, rather low and accounts, in most cases, for $<1$ rainstorm event. Even though the trends are low they are worth to be noted inspite of the low frequency of annual rainstorms (para 4.1, Fig. 2).

In case of negative trends, again the lowest category for weakest decreases predominantly occurs $(<0$ to -1 , Fig. 3$)$. The two larger categories were detected for a few stations only.

In spatial terms, it is worth questioning whether any regionalization according to positive or negative trends of rainstorm occurrences can be detected or not. It can be seen that over greater parts of Subtropical China a positive trend at slightly larger magnitudes ( $>1$ to 2 , and $>2$ events) can be experienced. On opposite, northern (Temperate) China experiences a complex pattern of positive and negative trends (which both belong to the lowest category, $>0$ to 1 , resp. $<0$ to -1 ) expressing a meager positive or negative trend.

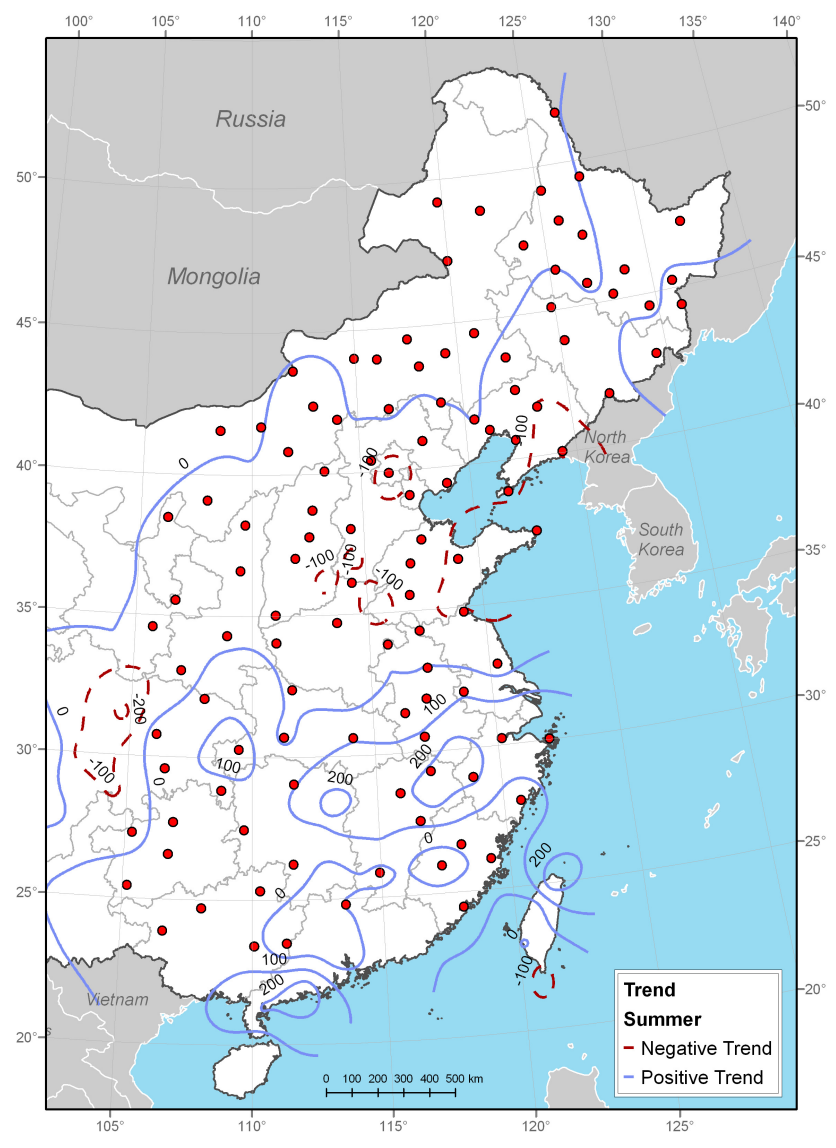

Fig. 9. Trend of summer (June-July-August) precipitation over East China, 1951-2000, $\mathrm{mm} / 50$ years

(Domroes and Schaefer, 2003)

\subsection{Occurrences of rainstorms during summer}

Rainstorms are chiefly experienced in the peak summer season (JJA, see para 3). In southern and southeastern China, the rainy season starts already in spring, but summer expresses the peak season of precipitation and, subsequently, of rainstorms. On opposite, winter does not experience rainstorms because of lacking or negligible precipitation. The number of summer rainstorms is however low (Fig. 4), mostly $<2$ events are experienced. The higher categories ( $>2$ to 3 and $>3$ to 4 events) are spatially limited, preferably to parts of southeastern China.

\subsection{Trend of occurrences of summer rainstorms}

The composition of the trend of occurrences of summer rainstorms shows a similar pattern as the annual trends (Fig. 5/Fig. 3). Increasing trends prevail at most stations, even at larger magnitudes $(>1)$. Decreasing trends, if occurring, are at the lowest magnitude $(<0$ to -1$)$. Spatially, positive (increasing) trends are to be seen at nearly all stations in south and southeastern (Subtropical) China whereas 


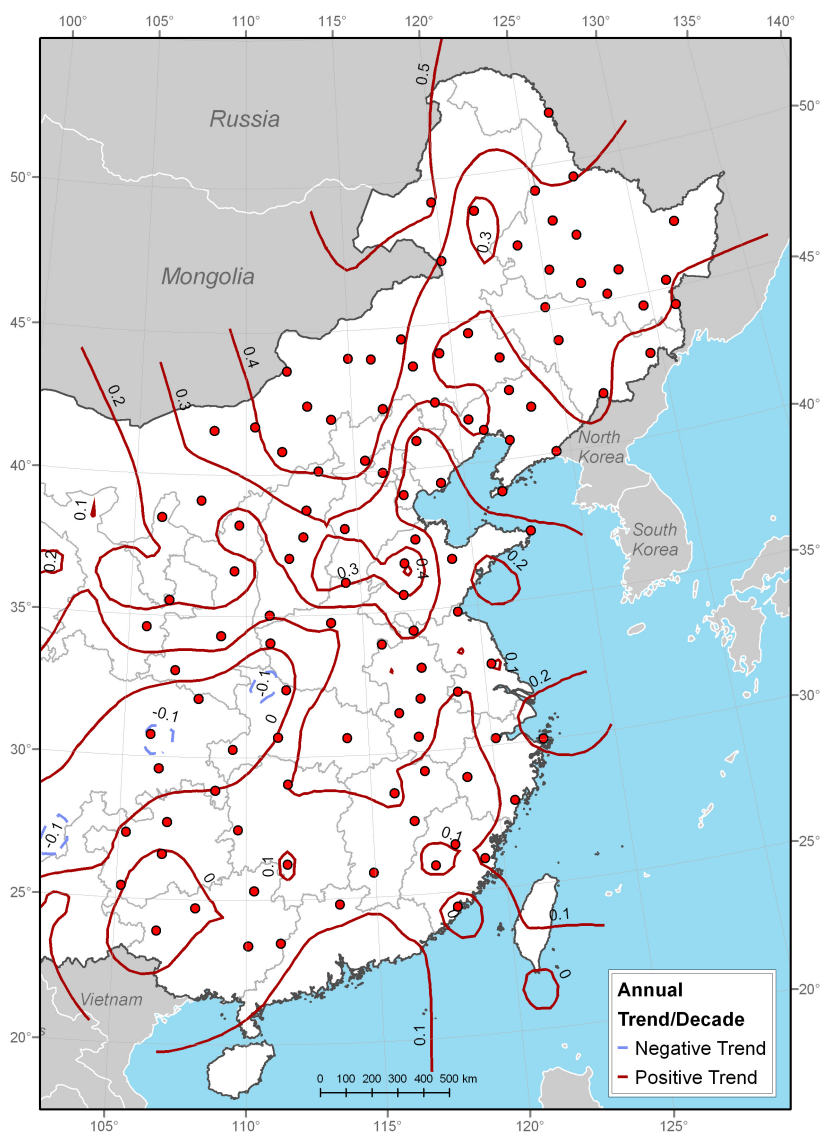

Fig. 10. Trend of annual temperature change over East China, 1951-2000, ${ }^{\circ} \mathrm{C} /$ decade

(Domroes and Schaefer, 2003)

a complex pattern of increasing and decreasing trends is shown for northern (Temperate) China.

\section{Discussion}

As a major observation, a positive (increasing) trend of rainstorm occurrences was observed, for mean annual and mean summer totals, at most stations over East China. Spatial trend patterns widely correspond between annual and summer totals showing synchronously a significantly increasing trend for Subtropical China while a complex pattern occurs for Temperate China. The highest increasing trends are observed over Subtropical China. Spatial differences in the trend of rainstorm occurrences, both in annual respects and for summer, may be correlated with the respective pattern of precipitation distribution over China.

Figure 6 shows the distribution of mean annual precipitation totals over East China, Fig. 7 the distribution of summer precipitation (in both cases for the period 1951-2000). A similar pattern of distribution can be observed showing the higher precipitation totals in Subtropical China and de-

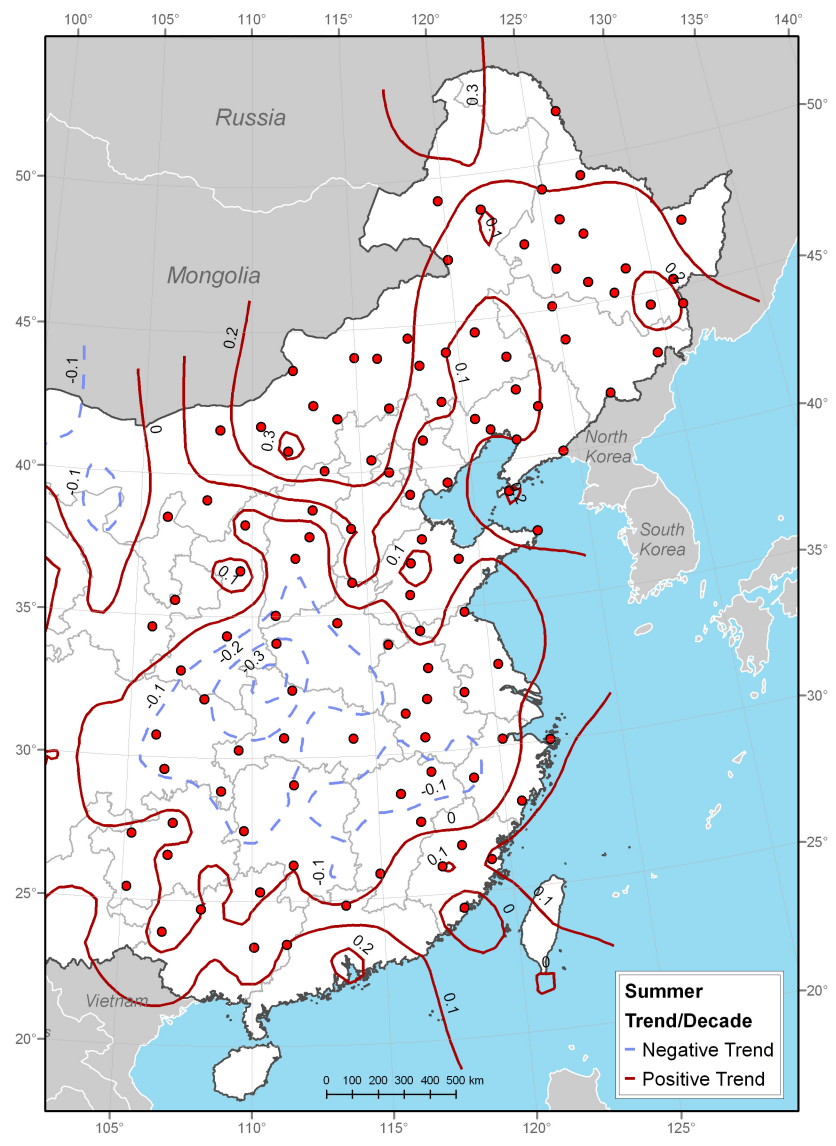

Fig. 11. Trend of summer temperature change over East China, 1951-2000; ${ }^{\circ} \mathrm{C} /$ decade

(Domroes and Schaefer, 2003)

creasing totals towards Temperate China. Accordingly, also the length of the wet season decreases (Domroes and Peng, 1988) and, synchronously, also the occurrences of rainstorms and their recent trend decrease (Figs. 2 and 4, resp. Figs. 3 and 5). The observations on the trend of rainstorms are remarkably correlated with the mean annual, resp. summer precipitation totals over East China (Domroes and Schaefer, 2003 and Figs. 8 and 9). In both cases, subtropical East China experiences greater totals of precipitation, and also a distinctive South-to-North-gradient of decreasing precipitation can be observed. It can be followed that a positive (increasing) trend of rainstorm occurrences seen for Subtropical China corresponds with greater precipitation totals while a negative (decreasing) trend of rainstorms corresponds with lower precipitation totals; this relationship can synchronously be observed for the annual and summer trends of rainstorms.

The detected greater trends of rainstorms over Subtropical China may also be correlated with the trends of annual precipitation and summer precipitation, respectively (Figs. 8 and 9). A positive relationship can be noted between the increasing annual precipitation and the increasing number 
of rainstorm events. For the trend of summer precipitation, both positive and negative trends can be observed over East China with predominantly increasing trends across Subtropical China. Same observations are given for the summer trend of precipitation. It is therefore confirmed that a greater frequency of rainstorms is directly correlated with a greater amount of precipitation and with the observed increased trends of precipitation, and vice-versa.

Within the climate change scenario (see IPCC Reports 2001 and 2007) it is also argued that the occurrences of rainstorms would increase as a consequence of global warming. Such possible relationship is not proved by the present study. It is, however, definitely proved (Domroes and Schaefer, 2003) that temperatures over China have even strikingly increased during the past 50 years, 1951-2000 (Fig. 10, isolines express the trends $\left[{ }^{\circ} \mathrm{C}\right]$ per decade). At 87 percent of all stations a positive trend was recorded. The weakest increase was observed over Subtropical China (mostly between 0.5$\left.1.0^{\circ} \mathrm{C} / 1951-2000\right)$. For the whole China, the annual warming trend is approximately double compared with the global trend (Domroes and Schaefer, 2003).

For the trend of summer temperatures over East China (Fig. 11), positive (increasing) trends occur over Temperate China while negative (decreasing) trends prevail over most parts of Subtropical China except the peripheral regions (Fig. 11). Trend values are, however, rather small (Fig. 11). As rainstorms mostly derive from singular weather anomalies at small localities, due to the nature of the monsoon dynamics, their correct spatial detection is therefore difficult and stationary observations at specific meteorological sites may not properly detect them. Spatial representation of stationary observations, especially for precipitation and rainstorms, is limited.

As southeastern China is frequently visited by typhoons the question arises to which extent rainstorms are correlated with typhoons. Such relationship would however affect the coastal areas only.

As the study has shown an increasing trend of rainstorms especially for Subtropical China, their adverse affect on the environment, both the physical and human (by soil erosion, landfalls and floods, respectively on housing and livelihood), needs to be considered.

Edited by: D.-D. Rousseau

\section{References}

Chen, K.-Y., Domroes, M., Hsu, S.-I., Schaefer, D., Yau, Y.-M., and $\mathrm{Hu}, \mathrm{C} .-\mathrm{Y} .:$ A study of the secular temperature increase in Taiwan compared with global warming, Geographical Research (Taiwan), 31, 1-13, 1999.

Domroes, M.: Observations on Recent Air Temperature Change in Taklimakan Desert, in: The Past, Present and Future of Desert, Proc. Int. Scientific Conference on the Taklimakan Desert,
Urumqi, China, 1993, Arid Zone Research, Supplement, 224236, 1995.

Domroes, M. and Peng, G.: The Climate of China, Springer-Verlag, Berlin, 1988.

Domroes, M. and Schaefer, D.: Variability of climatic change over time and space in China, in: Climates in Transition, edited by: Nkemdirim, L. C., Washington D.C., International Geographical Union, Commission on Climatology, 55-66, 2003.

National Climatic Data Center: Global Historical Climatology Network (Daily Version 1.0), http://www.ncdc.noaa.gov/oa/climate/ ghcn-daily/index.php, 21 June 2008.

IPCC: Climate Change 2001: Synthesis Report, A Contribution of Working Groups I, II, and III to the Third Assessment Report of the Integovernmental Panel on Climate Change, edited by: Watson, R. T. and the Core Writing Team, Cambridge University Press, Cambridge, United Kingdom, and New York, NY, USA, 398 pp., 2001.

IPCC: Climate Change 2007: The Physical Science Basis, Contribution of Working Group I to the Fourth Assessment Report of the Intergovernmental Panel on Climate Change, edited by: Solomon, S., Qin, D., Manning, M., Chen, Z., Marquis, M., Averyt, K. B., Tignor, M., and Miller, H. L., Cambridge University Press, Cambridge, United Kingdom and New York, NY, USA, 996 pp., 2007.

Ren, G. Y., Guo, J., Xu, M. Z., et al.: Climate changes of mainland China over the past half century, Acta Meteorol. Sin., 63(6), 942955, 2005 (in Chinese).

Schaefer, D.: Recent Temperature Trends and Rainfall Variabilities in Taiwan, in: Proceedings of the International Symposium on Climate Change and Variability and their Impacts, Commission on Climatology, 29th International Geographical Congress, Seoul 2000, 165-169, 2000.

Schaefer, D.: Rezente Klimaänderungen in China? Ein Vergleich mit globalen Trends, Geographische Rundschau, 10, 42-46, 2001.

Schaefer, D.: Recent Climate Change in China and possible impacts on Agriculture, in: Deutscher Tropentag 2001, Conference on International Agricultural Research for Development, Conference CD, 2001.

Schaefer, D.: Visualization of Climatic Change over Time and Space in China applying a WebGIS, in: Proceedings of the International Conference on Sustainable Water Resources Management in Changing Environment of the Monsoon Region, Vol. II, edited by: Herath, S., Pathirana, A., and Weerakoon, S. B., 477486, 2004.

Schaefer, D. and Domroes, M.: Recent temperature trends in Taiwan and their spatial and temporal variabilities, in: Proceedings of the International Conference on Climate Change and Climate Variability - Past, Present and Future, edited by: Mikami, T., 177-184, 2000.

Tao, S.: Severe rainstorms in China, Beijing, Science Press, 1980 (in Chinese). 